\title{
SEGURANÇA E SAÚDE DO TRABALHO EM FUMICULTORES COM CERTIFICAÇÃO DO SISTEMA DE GESTÃO INTEGRADO
}

\author{
Dalva Paulista Miaqui* \\ Cezar Augusto Romano** \\ Maria Aparecida Cassilha Zawadneak***
}

RESUMO: O Brasil é o segundo maior produtor de tabaco do mundo e o maior exportador do produto. No campo, há predomínio de produtores de agricultura familiar que produzem a matéria-prima, vendendo-a exclusivamente para a agroindústria do tabaco, sob Sistema de Integração de Produção. Nesse sistema, todos os trabalhadores envolvidos nos diferentes processos produtivos, inclusive fornecedores e subcontratados, devem seguir normas entre as quais as de Segurança e Saúde Ocupacional. O presente estudo objetivou verificar se a indústria fumageira com certificação do Sistema de Gestão Integrado está repassando as questões de Segurança e Saúde do Trabalho aos seus fornecedores de matéria-prima. O estudo foi conduzido em um município do Núcleo Regional de União da Vitória, PR. Para a coleta de dados foram realizadas entrevistas em 11 propriedades agrícolas, que comportam diretamente 29 trabalhadores rurais envolvidos na fumicultura. A metodologia utilizada foi de estudo de caso múltiplo, por meio de observação direta e entrevistas. As atividades realizadas nas propriedades pelos fumicultores na época de colheita e secagem do fumo caracterizaram-se pela carga horária média de trabalho de 11 horas. Observou-se falta de treinamento efetivo do modo de usar o Equipamento de Proteção Individual (EPI) e de procedimentos de sua manutenção. Os sintomas relacionados à Doença da Folha Verde do Tabaco (DFVT) ou intoxicações com agroquímicos informados pelos trabalhadores foram semelhantes nas diferentes propriedades. Os resultados obtidos demonstram a ausência de diferenciação no tema segurança e saúde do trabalho entre as indústrias com ou sem certificação do Sistema de Gestão Integrado na Região.

PALAVRAS-CHAVE: Tabaco; Agricultura familiar; Certificação SGI.

\footnotetext{
* Engenheira Agrônoma com especialização em MBA Gestão Ambiental e Engenharia de Segurança do Trabalho. Universidade Tecnológica Federal do Paraná (UTFPR). Brasil.

E-mail: dalva.paulista@gmail.com

** Doutor em Engenharia de Produção. Docente Associado-3 na Universidade Tecnológica Federal do Paraná (UTFPR), Brasil.

*** Doutora em Agronomia (Produção Vegetal) pela Universidade Federal do Paraná. Docente Associado do Departamento de Patologia Básica, do Setor de Ciências Biológicas, da Universidade Federal do Paraná (UFPR), Brasil.
} 


\title{
SAFETY AND HEALTH OF TOBACCO-GROWERS FEATURING INTEGRATED MANAGEMENT SYSTEM CERTIFICATION
}

\begin{abstract}
Brazil ranks second as a tobacco-grower and the greatest exporter of the product worldwide. Family agriculture predominates, with the production of prime matter sold exclusively to the tobacco agroindustry within the Integrated Production System. All workers involved in the different production processes, including suppliers and outsourcers, should follow the norms, particularly the Safety and Occupational Health rules. Current analysis, elaborated in the town of União da Vitoria, Brazil, verifies whether the tobacco industry with Integrated Management System certification is informing the issues in Work Safety and Health to the suppliers. Data were collected by interviews on eleven farms directly involving 29 rural workers specialized in tobacco-growth. A multiple case study was applied with direct observation and interviews. Activities on the farms during the tobacco harvest and tobacco drying are characterized by an 11-hour workday. Effective training in Individual Protection Equipment and its maintenance is lacking. Symptoms for the Green Tobacco Sickness (GTS) or intoxications by agro-chemicals notified by the workers were similar on the different farms. Results show the lack of differentiation in Work Safety and Health among the industries with or without the Integrated Management System certification in the region.
\end{abstract}

KEY WORDS: Tobacco; Family agriculture; IMG Certification.

\section{INTRODUÇÃO}

No Brasil, o cultivo de tabaco Nicotiana tabacum L. apresenta importância significativa por proporcionar o emprego de grande número de pessoas no campo e na indústria (CASTRO; MONTEIRO, 2015). No entanto, a exposição ocupacional durante o cultivo do fumo pode ocasionar graves problemas de saúde, pois o trabalhador fica exposto a constantes riscos (CARGNIN et al., 2016; ZIMMERMANN, 2009).

No município estudado, pertencente ao Núcleo Regional de União da Vitória - PR, o fumo ocupa área de 900 hectares e tem rendimento médio de 2.000 $\mathrm{kg} / \mathrm{ha}$ (IPARDES, 2016).

No ano de 2005, o Brasil aderiu à Convenção Quadro para o Controle do 
Tabaco (CQCT) mediante o compromisso de implementar o Programa Nacional de Diversificação em Áreas Cultivadas com Tabaco que tem como objetivo desenvolver alternativas saudáveis e economicamente viáveis à produção do fumo (CUNICO, 2013; BRASIL, 2011; ZIMMERMANN, 2009).

As indústrias, como diferencial competitivo visando melhorar seu desempenho e otimizar o uso de seus recursos, têm aderido aos Sistemas de Gestão Integrado que em conformidade com os padrões normativos da Associação Brasileira de Normas Técnicas - ABNT abrangem o Sistema de Gestão de Qualidade NBR ISO 9001; o Sistema de Gestão Ambiental NBR ISO 14001; a Norma Internacional OHSAS Occupacional Health and Safety Management Systems Series ou SGSSO - Sistema de Gestão em Segurança e Saúde Ocupacional 18001 e o Sistema de Gestão de Responsabilidade Social - SA 8000 (ZIMMERMANN, 2009).

Com a certificação, as empresas passam a cumprir requisitos que atendam responsabilidades de saúde e segurança do trabalho, entre outras, inclusive aos seus fornecedores de matéria-prima.

Questiona-se: a indústria fumageira com certificação do Sistema de Gestão Integrado está repassando as questões de segurança e saúde do trabalho aos seus fornecedores de matéria-prima?

\section{REVISÃO BIBLIOGRÁFICA}

Dados da Associação dos Fumicultores do Brasil - AFUBRA indicam que o Brasil é o segundo maior produtor de tabaco do mundo e o maior exportador do produto. No ano de 2015, a produção envolveu 619 municípios brasileiros, sendo que $97 \%$ da fumicultura se encontram na região Sul (AFUBRA, 2016).

A cultura é geradora de polêmicos debates, seja pelo consumo, produção ou destino dos recursos decorrentes desta cadeia produtiva (DESER, 2010; ZIMMERMANN, 2009).

O cultivo do fumo inicia-se com a produção das mudas que se dá nos meses de junho e julho, as sementes germinam de 12 a 15 dias após plantio (OLIVEIRA; COSTA; 2012). 
Em média 60 dias após o plantio das sementes as mudas atingem o ponto ideal para serem transplantadas para a lavoura, já com a área adubada, fase de intenso uso de agrotóxicos. Nesse período, o fumicultor monitora o crescimento e realiza o controle de pragas e doenças. Após, aproximadamente, 60 dias do transplante iniciase a colheita (OLIVEIRA; COSTA, 2012; SCHOENHALS, 2009).

$\mathrm{O}$ ciclo vegetativo percorre por um período de 210 dias, segue-se para a colheita, secagem, pré-classificação e, após o enfardamento, o produto é encaminhado para venda. Finalizada uma safra, inicia-se o preparo para a próxima, período conhecido como entressafra, fazem-se os reparos necessários na estufa, o corte de lenha para secagem, e novamente o preparo da terra (ALMEIDA 2005, apud HEMMANNN, 2009; OLIVEIRA; COSTA, 2012; CUNICO, 2013).

Além dos riscos oriundos da exposição por contato direto com a planta e trabalho a céu aberto, muitas vezes a topografia acidentada impede a utilização da mecanização, tornando o trabalho ainda mais intenso e desgastante, refletindose em dores físicas, problemas respiratórios, riscos de acidentes por quedas de equipamentos e máquinas (NUNES, 2010).

A jornada de trabalho da fumicultura se estende por todo o ano, entre as etapas da semeadura até o pagamento do produto (CUNICO, 2013).

Diante deste cenário, a indústria do tabaco buscou como estratégia empresarial, a implantação do Sistema de Gestão Integrado (SGI) que abrange as normas internacionais: ISO 9001 - Gestão da Qualidade: visa fornecer produtos que atendam aos requisitos do cliente e aos requisitos regulamentares aplicáveis; ISO 14001 - Gestão Ambiental: visa controlar os impactos das atividades, produtos e serviços sobre o meio ambiente; OHSAS 18001 - Sistema de Gestão de Segurança e Saúde Ocupacional: visa controlar os riscos de segurança e saúde ocupacional, bem como melhorá-las continuamente; SA 8000 de Responsabilidade Social: visa melhorar as condições de trabalho e promover o respeito aos direitos dos trabalhadores (ZIMMERMANN, 2009).

No campo predomina a mão-de-obra familiar, geralmente em Sistema Integrado de Produção de Tabaco com uma indústria da área. Neste sistema é firmado contrato que estabelece deveres e obrigações entre as partes (DESER, 2010).

A indústria fica comprometida em fornecer assistência técnica gratuita, 
repassar apenas insumos certificados e aprovados para uso no fumo, avalizar o custeio de insumos e de transporte da produção além de adquirir integralmente toda a safra por preços negociados com a representação dos agricultores. Ao produtor rural fica fixado o volume a ser produzido e entregue na sua totalidade para a indústria contratante, utilizar somente os produtos recomendados pela indústria e assumir os custos dos insumos e infraestrutura exigidos em todo o processo de produção (DESER, 2010; SCHOENHALS, et al., 2009).

Iório (1994 apud FILHO, 2003, p. 28) define o Sistema Integrado de Produção Agroindustrial.

Mediante um contrato formal ou verbal o pequeno produtor passa a produzir determinada matéria-prima, vendendo-a exclusivamente para a agroindústria com a qual tem contrato, a agroindústria por seu turno se encarrega da assistência técnica, do fornecimento de insumos e, as vezes do financiamento das instalações necessárias e, ao final de cada safra, da compra da produção (FILHO, 2003, p. 28).

A Doença da Folha Verde do Tabaco (DFVT) é adquirida quando ocorre o contato do trabalhador com o fumo verde úmido, pela exposição à nicotina presente nas folhas (SINDITABACO, 2016). A utilização correta de Equipamento de Proteção Individual (EPI) auxilia na redução da quantidade de nicotina absorvida, consequentemente, reduz o risco da denominada DFVT, assim como o risco de intoxicação por agrotóxicos (CARGNIN et al., 2016).

Com relação à aplicação dos agrotóxicos, Beck (2013) mencionou que o uso correto dos EPI's é uma exigência da legislação brasileira, pois as indústrias produtoras utilizam os rótulos, bulas e Fichas de Informação de Segurança de Produtos Químicos (FISPQ's), que trazem informações sobre os procedimentos e tipos de EPI necessários para a manipulação e aplicação de cada produto.

A Norma Regulamentadora - NR 31 tem como objetivo estabelecer os preceitos a serem observados na organização e no ambiente de trabalho, de forma a tornar compatível o planejamento e o desenvolvimento das atividades de agricultura, pecuária, silvicultura, exploração florestal e aquicultura (BRASIL, 2005, p. 1). O item 31.6 da NR 31 traz no título "Serviço Especializado em Segurança e Saúde no Trabalho Rural - SESTR" e subtítulo 31.6.1. 
O SESTR, composto por profissionais especializados, consiste em um serviço destinado ao desenvolvimento de ações técnicas, integradas às práticas de gestão de segurança, saúde e meio ambiente de trabalho, para tornar o ambiente de trabalho compatível com a promoção da segurança e saúde e a preservação da integridade física do trabalhador rural (BRASIL, 2005, p. 4).

No título 31.7 Comissão Interna de Prevenção de Acidentes do Trabalho Rural - CIPATR e subtítulo 31.7.1.

A CIPATR tem como objetivo a prevenção de acidentes e doenças relacionados ao trabalho, de modo a tornar compatível permanentemente o trabalho com a preservação da vida do trabalhador (BRASIL, 2005, p. 6).

\section{METODOLOGIA}

O estudo foi desenvolvido em 11 propriedades localizadas em município do Núcleo Regional do município de União da Vitória, no Estado do Paraná, abrangendo, aleatoriamente, 29 produtores rurais que cultivam o fumo pelo sistema de produção Virginia ou de Estufa do qual se exigia a cura das folhas em estufa.

Os dados foram coletados durante o mês de novembro de 2016, em propriedades vinculadas ao Sistema Integrado de Produção de Tabaco com três diferentes indústrias, das quais duas possuíam a certificação do Sistema de Gestão Integrado (SGI) compreendendo dez propriedades e a $11^{\mathrm{a}}$ propriedade estava integrada a uma indústria sem esta certificação servindo como parâmetro com as demais.

Como instrumento de pesquisa foi utilizado questionário semiestruturado com questões abertas e fechadas, elaborado com o tema saúde e segurança do trabalho, a partir de pesquisa bibliográfica em livros, trabalhos acadêmicos, revistas e legislação.

A entrevista semiestruturada, aplicada pela pesquisadora, permitiu aos trabalhadores entrevistados abertura de resposta e comentários a respeito das questões abordadas, permitindo o enriquecimento do estudo. 
O desenvolvimento da pesquisa teve as seguintes etapas: estudo prévio da problemática das condições de segurança e saúde dos trabalhados da fumicultura, identificação das indústrias detentoras de certificação do SGI, revisão bibliográfica, elaboração das questões, entrevista com o fumicultor, transcrição das respostas e análise dos dados, apresentação dos resultados e discussões.

A metodologia científica utilizada na pesquisa foi de estudo de caso múltiplo por meio de observação direta junto aos trabalhadores e à aplicação de entrevista.

\section{RESULTADOS E DISCUSSÕES}

\subsection{DADOS GERAIS DA FUMICULTURA}

A área destinada ao cultivo do fumo variou de 2 a 6 hectares, com produção média de $1.700 \mathrm{~kg} / \mathrm{ha}$. Somente um dos proprietários comprava a muda de outra propriedade, sendo que as demais exerciam todas as atividades, desde a semeadura até a entrega dos fardos ao caminhão da indústria.

A experiência na atividade da fumicultura era em média de 10,9 anos, com amplitude de dois a 35 anos. Em alguns casos, a atividade era repassada de pai para filho e, no decorrer dos anos, houve mudança de contrato com outra indústria. Ficou evidenciado que tanto menores de 14 anos quanto maiores de 60 exerciam atividades na fumicultura. Porém, pelo conhecimento da proibição do exercício de trabalho infantil e de idosos, os proprietários omitiam esta informação.

Foram observados três sistemas de plantio no sistema integrado de produção: direto; convencional e de transição para a produção integrada. Os diferentes sistemas de cultivos faziam uso de diferentes processos de manejo diferenciado, consequentemente, refletindo em mudanças também nas condições de trabalho e exposição a agentes de risco ocupacional.

A diversificação de culturas, verificada em nove propriedades, não estava vinculada com a CQCT que visava atender ao Programa Nacional de Diversificação em Áreas Cultivadas com Tabaco por meio de criação de alternativas saudáveis e economicamente viáveis à produção do fumo, e sim, como uma necessidade de 
remuneração complementar à renda do fumo.

No período de colheita do fumo observou-se diferenciação nas propriedades quanto ao número de trabalhadores, na carga horária de trabalho principalmente pela necessidade de acompanhamento do processo de secagem noturna. As atividades eram mais intensas exigindo em média quatro trabalhadores, com carga horária média de 11 horas de trabalho por dia, de domingo a domingo. Nesta época fazia-se necessária a troca de dias de trabalho com outros agricultores do fumo como alternativa para suprir a demanda de mão de obra. A cura das folhas exigia a manutenção do forno e a atenção de um trabalhador por 24 horas por dia, por sete dias consecutivos de secagem. No período de não colheita não havia a necessidade de demanda externa de trabalhadores, sendo que em média empregavam três trabalhadores da propriedade, de segunda a sábado com carga horária diária individual de 07 horas de trabalho.

A extensa carga horária de trabalho de fumicultores também foi verificada em estudo realizado por Heemann (2009), que constatou uma média de 11,53 horas trabalhadas nas diferentes atividades das propriedades de fumicultores e confirmada por Cunico (2013) para os períodos de colheita e secagem (HEEMANN, 2009; CUNICO, 2013).

Os cuidados na lavoura, conciliados com os cuidados na secagem, inclusive noturna, são essenciais para uma boa classificação do fumo. A garantia de coleta de todas as folhas com a cura (secagem) adequada resultam na boa classificação, que corresponde à qualidade do produto e melhor remuneração da safra. A necessidade de cura por meio de estufa, característica do Sistema Produtivo Virgínia, torna-se um agravante para a saúde do trabalhador pelo fato de ter que se manter em alerta por todo o período noturno, podendo gerar distúrbios do sono, acidentes com queimaduras e exposição a ambientes de trabalho precários aumentando os riscos ocupacionais (CUNICO, 2013).

Foi verificado que a atividade da fumicultura ocorria de três diferentes formas: estufa de grampos, estufa de granel ou folha solta e estufa de cabinho. Esta diferenciação se dava a partir do recebimento das folhas, para secagem. O modelo de estufa adotado correspondia ao processo de produção, adotado pela indústria. No entanto, alguns produtores copiavam a estufa do vizinho quando verificavam 
melhor funcionalidade ou utilização de menor mão de obra, sem o aval ou por omissão da indústria integradora.

As visitas técnicas do representante da indústria ocorriam numa média de 5,1 vezes ao ano. Segundo os produtores as visitas deveriam ocorrer uma vez ao mês, ou seja, no mínimo 12 visitas ao ano, caso fosse cumprido com o contrato de integração. Esta ausência de visitas técnicas pode gerar consequências negativas tanto na quantidade como na qualidade do tabaco, comprometendo a renda do produtor, gerando prejuízos ao meio ambiente por não ter o monitoramento do manejo agrícola e aperfeiçoamento de tecnologias agrícolas, bem como, a segurança e a saúde do trabalhador por falta de subsídios básicos sobre questões de prevenção de risco do dia a dia de trabalho.

\subsection{USO DE EQUIPAMENTO DE PROTEÇÃO INDIVIDUAL}

Foi verificado que os trabalhadores faziam uso de EPI, no entanto, o modo de vestir e retirar de tais equipamentos não estavam de acordo com o recomendado pelas Fichas de Inspeção de Segurança de Produto Químico - FISPQ. As indústrias reconheciam a necessidade de uso de EPI, pela DFVT e uso de agroquímicos, mas não ocorria treinamento efetivo do modo de usar e de procedimentos de manutenção. Os EPI's eram fornecidos por meio de solicitação do produtor às indústrias e seu valor descontado do produtor no acerto da safra com a indústria.

Em todas as propriedades, as folhas eram manipuladas quando úmidas, pois existia a necessidade de trabalhar bem cedo ainda com o orvalho presente nas folhas ou mesmo em dias chuvosos para não ocorrer perda por folha passada do ponto de amadurecimento.

Foi relatado, pelos trabalhadores, que mesmo usando EPI a água passava pela luva, entrando em contato com a pele. Logo, existia o contato com a nicotina pela entrada da água infiltrada pelo EPI, não necessariamente manipulando as folhas sem luvas. Um dos trabalhadores considerou: "o grudentinho fica na roupa". 
Os sintomas náusea, vômito, tontura, alucinação, dor de cabeça, fraqueza, formigamento, agitação do sangue, insônia, delírio, informados pelos trabalhadores em relação à exposição à nicotina foram semelhantes nas diferentes propriedades e já haviam sido encontrados em literatura (CARGNIN et. al., 2016; SILVA, 2011; HEEMANN, 2009).

Os sintomas passavam naturalmente após 24 horas ou se fazia uso de remédio conhecido entre os fumicultores como "amargo" ou "xaropão" e após 02 a 03 horas, se os sintomas desaparecessem, os trabalhadores voltavam ao trabalho.

Foi observado que, em relação aos agrotóxicos, a indústria entregava todos os produtos a serem utilizados durante a safra, mas quem determinava o momento de fazer o uso era o próprio agricultor. As três diferentes indústrias repetiam as recomendações dos mesmos produtos químicos, tendo pequena variação, possivelmente decorrente de particularidades de manejo de cada propriedade.

Os inseticidas apareceram em maior número, num total de nove produtos nas 11 propriedades. Os herbicidas apareceram num total de sete diferentes produtos. Três diferentes tipos de fungicidas foram relatados. O antibrotante era o mesmo em todas as propriedades.

As classificações toxicológicas verificadas foram: Classe I - extremamente tóxico, Classe II - altamente tóxico, Classe III - medianamente tóxico e Classe IV pouco tóxico, tornando-se indispensável o uso de EPI durante todo o período em que o produto se mantém presente na lavoura. As diferentes classes toxicológicas sugerem um indicativo de que os efeitos no organismo podem se manifestar por diferentes sintomas. Foi observado, nas declarações prestadas pelos trabalhadores, sintomas como tontura, mal-estar, náusea, tosse, aumento da salivação, dores na coluna, dores no corpo, gosto amargo na boca, dor de cabeça, irritação ocular, cansaço extremo, falta de apetite, tristeza, alergia (pernas coçam), cólica e diarreia.

Somam-se às diferentes características químicas dos produtos, as quantidades absorvidas pelo organismo, o tempo de exposição ao agente químico e condições gerais de saúde de cada trabalhador (VEIGA, 2007; apud ASCARI, 2012).

Muitos trabalhadores apresentavam problemas em usar o EPI, pelo desconforto no uso, mas todos disseram usar EPI. A presente pesquisa demonstrou a falta de recomendação do uso de EPI para os trabalhadores rurais, fornecidos 
pela indústria do fumo, uma vez que os trabalhadores usuários parecem não serem ouvidos. Neste contexto, visualiza-se a importância da implantação do Serviço Especializado em Segurança e Saúde no Trabalho Rural que visa tornar o ambiente de trabalho compatível com a promoção da segurança e saúde e a preservação da integridade física do trabalhador rural, concomitante à Comissão Interna de Prevenção de Acidentes do Trabalho Rural que tem como objetivo prevenir os acidentes e as doenças relacionados ao trabalho (BRASIL, 2005). Deve-se destacar a importância do fumicultor para a indústria do fumo que depende dos seus serviços para alimentar toda a cadeia produtiva, com ou sem vínculo empregatício.

Em estudo realizado por Inácio (2011), foi verificado que o desconforto é o principal motivo pelos quais os agricultores não fazem uso de tal equipamento, apontando como segundo fator o alto custo (INÁCIO, 2011).

\subsection{CONHECIMENTO DOS TERMOS SST; SGI; NR 31 E CQCT PELOS TRABALHADORES}

Dentre os termos Segurança e Saúde do Trabalho - SST; Sistema de Gestão Integrado - SGI; Norma Regulamentadora 31 - NR 31; Convenção Quadro de Controle do Tabaco - CQCT, a pesquisa mostrou que o termo SST foi reconhecido em seis propriedades $(54,54 \%)$ e o termo SGI foi reconhecido em apenas uma $(9,09 \%)$ propriedade. Os termos: NR 31 e CQCT são desconhecidos em todas (100\%) as propriedades. Deve ser ressaltado que estas normas representam o dia a dia do setor da fumicultura, o que engloba os trabalhadores envolvidos nesta cadeia, como apregoado pela indústria. Assim, há a necessidade de acompanhamento destes trabalhadores por outras instituições que não sejam apenas pelas indústrias, uma vez que se evidenciou não haver interesse por parte destas em levar ao trabalhador maior conhecimento da exposição dos riscos de trabalho ao qual estão submetidos. 


\section{CONCLUSÃO}

Foi verificado que a indústria do fumo não fornece treinamento periódico relacionado ao tema segurança e saúde do trabalho aos seus fornecedores de matéria-prima, trabalhadores rurais. Portanto, não ocorre o cumprimento das medidas estabelecidas pelo sistema de gestão integrado. Sugere-se a realização de estudos futuros referentes às atividades diárias dos fumicultores perante a aplicação da norma regulamentadora - NR 31, uma vez que esta é a norma que regulamenta as medidas de segurança e saúde do trabalho das atividades de agricultura, pecuária, silvicultura, exploração florestal e aquicultura.

\section{REFERÊNCIAS}

AFUBRA. Associação dos Fumicultores do Brasil. Disponível em: < http://www. afubra.com.br/perfil-fumicultor.html> . Acesso em: 26 jul. 2016.

BECK, P. C. L. A Produção de Tabaco e as Doenças que Afetam os Agricultores pela Exposição Ocupacional. 2013. 44f. Trabalho de Conclusão de Curso (Curso de Graduação Tecnológica em Desenvolvimento Rural - PLAGEDER) - Faculdade de Ciências Econômicas da UFRGS, Cachoeira do Sul, 2013.

BRASIL. Ministério do Trabalho e Emprego. Norma Regulamentadora (NR 31), Segurança e saúde no trabalho na agricultura, pecuária, silvicultura, exploração florestal e aquicultura. Portaria n. 86, de 03/03/05 - DOU de 04/03/05. Disponível em: $<$ http://www.maconsultoria.com/arquivos/9fb3954fa1c54be7baca3ea73561e7e2. pdf $>$. Acesso em: 29 out. 2016.

CARGNIN, M. C. dos S.; TEIXEIRA, C. de C.; MASTOVANI, V. M.; LUCENA, A. de F.; ECHER, I. C. Cultura do Tabaco Versus Saúde dos Fumicultores, 2016. Disponível em: < http://www.scielo.br/pdf/tce/v25n2/0104-0707-tce-25-02-2940014. pdf $>$. Acesso em: 11 out. 2016.

CASTRO, L. S. P. de; MONTEIRO, J. K. Fumicultores advertem: a causa do seu sofrimento é a exploração no trabalho. Psicologia \& Sociedade, v. 27, n. 1, 
p. 87-97, 2015. Universidade do Vale do Rio dos Sinos, São Leopoldo/RS, Brasil. Disponível em: <http://www.ufrgs.br/seerpsicsoc/ojs2/index.php/seerpsicsoc/ article/view/3852/2478> . Acesso em: 10 out. 2016.

CUNICO, M. D. A percepção de riscos ocupacionais pelos fumicultores das comunidades de Itaíba (Marmeleiro - PR) e Volta Grande (IRATI - PR). 2013. 116f. Dissertação (Mestrado) - Universidade Tecnológica Federal do Paraná. Programa de Pós-Graduação em Desenvolvimento Regional, Pato Branco (PR), 2013.

DALLAGO FILHO, A. Avaliação da relação produtor: empresa no sistema integrado de produção agrícola na cultura de fumo. 2003. 99f. Dissertação de Mestrado em Administração da Universidade Federal do Rio Grande do Sul. Porto Alegre, 2003.

DESER. Departamento de Estudos Socioeconômicos Rurais. Tabaco, da Produção ao Consumo, uma cadeia de Dependência. Revista do Departamento de Estudos Sócio-Econômicos Rurais. Curitiba (PR), ago. 2010. Disponível em: < http://www. deser.org.br/publicacoes/revistaTabacoElabora\%C3\%A7\%C3\%A3oDeser-ACT.pdf > . Acesso em: 11 ago. 2016.

HEEMANN, F. O cultivo do fumo e condições de saúde e segurança dos trabalhadores rurais. 2009. 170f. Dissertação (Engenharia de Produção) Universidade Federal do Rio Grande do Sul, Porto Alegre, 2009.

INÁCIO, A. F. Exposição Ocupacional e Ambiental a Agrotóxicos e Nicotina na Cultura de Fumo do Município de Arapiraca. 2011. 100f. Dissertação (Doutorado) - Escola Nacional de Saúde Pública Sérgio Arouca, Rio de Janeiro, 2011.

IPARDES. Instituto Paranaense de Desenvolvimento Econômico e Social. Caderno Estatístico. Disponível em: < http://www.ipardes.gov.br/>. Acessado em: 05 jan. 2017.

NUNES, G. C. Uso do EPI: Equipamentos de Proteção Individual nas pequenas propriedades rurais produtoras de fumo no Município de Jacinto Machado, SC. 2010. 59 f. Monografia (Especialização em Engenharia de Segurança do Trabalho) Universidade do Extremo Sul Catarinense - UNESC, 2010.

OliVEIRA, F. de; COSTA M. C. F. Cultivo de Fumo (Nicotiana tabacum L.). 
Universidade de São Paulo - USP, 2012.Disponível em: < http://respostatecnica.org. br/dossie-tecnico/downloadsDT/NTcwMg > . Acessado em: 19 out. 2016.

RIBEIRO NETO, J. B. M. Sistemas de gestão integrados: qualidade, meio ambiente, responsabilidade social, segurança e saúde no trabalho. 4. ed. rev. São Paulo: Senac. São Paulo, 2013.

SCHOENHALS, M.; FOLLADOR, F. A. C.; SILVA, C. da. Análise dos impactos da fumicultura sobre o meio ambiente, à saúde dos fumicultores e iniciativas de gestão ambiental na indústria do tabaco. Rev. Engenharia Ambiental, Espírito Santo do Pinhal, v. 6, n. 2, p. 16-37, maio/ago. 2009.

SILVA, F. R. da. Risco ocupacional em fumicultores: genotoxicidade associada a susceptibilidade genética. 2011. $171 \mathrm{f}$. Tese (Genética e Biologia Molecular) Universidade Federal do Rio Grande do Sul, Porto Alegre, 2011.

SINDITABACO - Sindicato Interestadual da Indústria do Tabaco, 2016. Disponível em < http://sinditabaco.com.br/> Acesso: 05 ago. 2016.

VEIGA, M. M. Agrotóxicos: eficiência econômica e injustiça socioambiental. Ciência e Saúde Coletiva, Rio de Janeiro, v. 12, n. 1, p. 145-152, jan./mar. 2007. Disponível em: < http://www.scielo.br/pdf/csc/v12n1/13.pdf> . Acessado em: 15 jan. 2017.

ZIMMERMANN, M. Convenção-quadro para o controle do tabaco: perspectivas da fumicultura na região sul do Brasil. 2009. Dissertação (Mestrado profissional em Gestão de Políticas Públicas) -Universidade do Vale do Itajaí - UNIVALI, 2009.

Recebido em: $17 / 08 / 2017$

Aceito em: 27/11/2018 